\title{
Ictal EEG patterns in epilepsy with centro-temporal spikes
}

\author{
Giuseppe Capovilla ${ }^{\mathrm{a}, *}$, Francesca Beccaria ${ }^{\mathrm{a}}$, Amedeo Bianchi ${ }^{\mathrm{b}}$, Maria Paola Canevini ${ }^{\mathrm{c}}$, \\ Lucio Giordano $^{\mathrm{d}}$, Giuseppe Gobbi ${ }^{\mathrm{e}}$, Massimo Mastrangelo ${ }^{\mathrm{f}}$, Cinzia Peruzzi ${ }^{\mathrm{g}}$, \\ Tiziana Pisano $^{\mathrm{h}}$, Pasquale Striano ${ }^{\mathrm{i}}$, Pierangelo Veggiotti ${ }^{\mathrm{j}}$, Aglaia Vignoli ${ }^{\mathrm{c}}$, Dario Pruna ${ }^{\mathrm{h}}$ \\ ${ }^{a}$ Epilepsy Center, Department of Child Neuropsychiatry, C. Poma Hospital, 46100 Mantova, Italy \\ ${ }^{\mathrm{b}}$ Epilepsy Centre, Department of Neurology, San Donato Hospital, Arezzo, Italy \\ ${ }^{\mathrm{c}}$ Epilepsy Centre, San Paolo Hospital, University of Milan, Italy \\ ${ }^{\mathrm{d}}$ Department of Child and Adolescent Neuropsychiatry, Spedali Civili, Brescia, Italy \\ ${ }^{\mathrm{e}}$ Child Neurology and Psychiatry Unit, Neuroscience Department, Maggiore Hospital, Bologna, Italy \\ ${ }^{\mathrm{f}}$ Pediatric Neurology Unit, V. Buzzi Hospital, A.O. ICP, Milan, Italy \\ ${ }^{\mathrm{g}}$ Child Neuropsychiatry, Ospedale Maggiore, Novara, Italy \\ ${ }^{\text {h }}$ Child Neurology and Psychiatry, A.O.U. Cagliari, Cagliari, Italy \\ ${ }^{\mathrm{i}}$ Muscular and Neurodegenerative Diseases Unit, Institute G. Gaslini, University of Genova, Genova, Italy \\ ${ }^{\mathrm{j}}$ Child Neuropsychiatry and EEG Unit, 'C. Mondino' Institute of Neurology, Pavia, Italy
}

Received 30 March 2010; received in revised form 4 June 2010; accepted 7 June 2010

\begin{abstract}
Purpose: To describe the EEG pattern of seizures in patients with benign childhood epilepsy with centro-temporal spikes (BCECTS). Methods: The clinical and EEG data of 701 BCECTS patients with at least a 3 years follow-up were reviewed from 10 epilepsy centers. Results: Thirty-four seizures were recorded in 30 patients. Four different ictal EEG patterns (A-D) were identified. The most frequent (pattern A) was characterized by low voltage activity of fast rhythmic spikes, increasing in amplitude and decreasing in frequency, and occurred in 14 children. Pattern B (six patients) was constituted by a discharge of spikes intermixed with sharp waves increasing in frequency and amplitude. Pattern C (seven children) consisted of monomorphic theta which progressively formed a discharge increasing in amplitude and decreasing in frequency. Pattern D ( 5 children) was characterized by a initial focal depression of the electrical activity, followed by one of the three above described patterns. In 21 out of 28 children, the initial ictal pattern, altered from one pattern to another one. No clinical or EEG feature was predictive of a specific ictal pattern. Discussion: We failed to identify a unique ictal EEG pattern in our patients with BCECTS. The occurrence of per-ictal features, e.g., initial EEG depression or postictal slowing, is common and should not be interpreted with prejudice. Alteration of ictal EEG pattern from one to another is not in conflict with the diagnosis of BCECTS.
\end{abstract}

(C) 2010 The Japanese Society of Child Neurology. Published by Elsevier B.V. All rights reserved.

Keywords: BCECTS; Rolandic epilepsy; EEG; Benign epilepsy; System epilepsy

\section{Introduction}

Benign epilepsy with rolandic or centro-temporal spikes (BCECTS) is a focal epilepsy of childhood char-

\footnotetext{
${ }^{*}$ Corresponding author. Tel.: +39 0376 201371; fax: +39 0376 201372.

E-mail addresses: pippo.capovilla@aopoma.it, giuseppe.capovilla@aopoma.it (G. Capovilla).
}

acterized by absence of neurological deficits, motor focal seizures, peculiar EEG abnormalities and spontaneous recovery $[1,2]$. BCECTS is the most common form of idiopathic epilepsy in children [2], but, since seizure frequency is generally low in this syndrome, there are scarce descriptions of the ictal discharge [3-9] due to the difficult to capture the episodes. The first described ictal patterns are characterized by a sequence of rhythmic sharp waves or by a sequence of spikes remaining 
quite monomorphous throughout the discharge, not followed by significant signs of post-ictal abnormalities $[3,4]$. In 1990, Gutierrez et al. described an ictal subclinical event in a child with BCECTS characterized by a pattern of multiple spike and wave complexes, followed by post-ictal slowing [5]. Oliveira de Andrade, in 2005, reported two subclinical rhythmic discharges of spike and wave in a boy with BCECTS [8]. Saint-Martin et al. in 2001, described a series of patients presenting with different types of positive or negative ictal manifestations. In four cases the description of focal seizures was given [10]. Dalla Bernardina et al. in 2005, wrote that, generally, the ictal pattern is characterized by a sequence of rhythmic sharp waves or spikes, not preceded by an important EEG depression, remaining unchanged during the seizure and not followed by post-ictal slowing [1]. The aim of our paper is to describe BCECTS patients in which electroclinical and/or subclinical seizures were recorded and to compare our to literature data.

\section{Patients and methods}

Approval from the local institutional Ethic Committee and informed consent signed by the parents were obtained. We reviewed clinical and EEG documentation of our cases with BCECTS (701 patients) referred to 10 different Epilepsy Centre in Italy, with at least 3 year follow-up. Strict inclusion criteria were the presence both of typical sensorimotor seizures affecting orofacial district with or without generalization and focal interictal EEG paroxysms in the centro-temporal areas activated by drowsiness and sleep. Furthermore, all patients fulfilled the classic criteria for BCECTS: normal pregnancy and delivery, uneventful past medical history, normal psychomotor development at diagnosis, normal neuroimaging, onset between 2 and 13 years, spontaneous recovery [1113]. From clinical charts we selected these informations: sex, age, age at seizure onset, personal antecedents of febrile seizures, family history of epilepsy and or febrile seizures, neurological and neuropsychological evaluations, neuroimaging, interictal EEG and ictal video-EEG, antiepileptic drugs (AEDs) prescribed. All patients had repeated and prolonged EEG recordings, performed both at awake state and during sleep. Scalp silver-silver chloride electrodes were placed using the International 10-20 system. Additional electrodes were used for polygraphic parameters, in particular for muscular poligraphy. All examinations were recorded on split-screen video-EEG. All interictal and ictal patterns were reviewed by two investigators (GC and FB). Subclinical seizures were defined by the occurrence of an ictal discharge without concomitant clinical manifestations detected by video-EEG. The correlation between the identified ictal patterns and the clinical-
EEG data of the patients (i.e., side of ictal abnormalities, occurrence of secondary generalization or postictal slowing, presence of drug-resistance), were analyzed by two-way analysis of $\chi^{2}$ with Yates' correction, with $p<0.05$ taken as significant.

\section{Results}

From 701 BECTS patients, we recorded subclinical and/or clinical seizures in 30 patients ( 20 males).

\subsection{Demographic data}

Clinical characteristics of the patients are shown in Table 1. All the patients had an uneventful personal history. In four patients, seizure onset was preceded by simple febrile seizures. A positive family history of epilepsy is present in 10 cases, mostly for idiopathic forms. In adjunction, four cases had a positive family history for febrile seizures, two cases had a positive family history for both epilepsy and febrile seizures.

\subsection{Onset age}

The age at epilepsy onset varied between 2 and 11 years (mean 6 years 4 months), and does not differ from the cases reported in the literature.

\subsection{Seizure semeiology}

\subsubsection{Referred by parents}

All the patients presented with typical lateralized motor faciobrachial seizures during drowsiness, sleep or awakening. At awake state, the seizures were present in nine cases. A secondary generalization was referred by the parents in eight cases.

\subsubsection{Video-recorded}

In two cases the seizures were only subclinical. Three cases presented with both clinical and subclinical seizures in different EEG recordings. In the other cases, the patient presented with a wide spectrum of polymorphous clinical episodes. The duration of the attacks was comprised between $10 \mathrm{~s}$ and 15 min (mean 1 min and $40 \mathrm{~s})$. Ictal manifestations are detailed in Table 2.

\subsection{Neuropsychological profile}

Psychomotor development before seizure onset was normal, as neuroimaging with MRI/CT scan (26/4 patients, respectively). Eight children (Case 1, 10-13, 19, 21 and 22) experienced transient learning difficulties and mild attention deficit or behavioural problems during epilepsy history, completely recovered at the end of follow-up. 
Table 1

Clinical characteristics of the patients.

\begin{tabular}{|c|c|c|c|c|c|c|c|c|c|c|c|}
\hline Patient no. & Sex & Age epilepsy onset & $\begin{array}{l}\text { Seizure } \\
\text { frequency }\end{array}$ & $\begin{array}{l}\text { Seizure } \\
\text { occurence }\end{array}$ & $\begin{array}{l}\text { Post-ictal } \\
\text { deficit }\end{array}$ & Seizures recorded & Development & $\begin{array}{l}\text { Follow-up } \\
\text { (years) }\end{array}$ & Therapy & $\begin{array}{l}\text { AEDs } \\
\text { RES }\end{array}$ & $\begin{array}{l}\text { AED at time } \\
\text { of seizures recording }\end{array}$ \\
\hline 1 & M & 7 years 3 months & PA & $\mathrm{A}, \mathrm{S}$ & - & Clinical & $\begin{array}{l}\text { Transient } \\
\text { attention deficit }\end{array}$ & 18 & VPA & No & Yes \\
\hline 2 & $\mathrm{M}$ & 6 years 8 months & PA & $\mathrm{S}$ & Yes & Subclinical & Normal & 5 & CLB & Yes & No \\
\hline 3 & $\mathrm{~F}$ & 4 years 6 months & M & $\mathrm{A}, \mathrm{S}$ & Yes & Clinical & Normal & 5 & - & & No \\
\hline 4 & M & 5 years 9 months & M & $\mathrm{S}$ & - & Sublinical & Normal & 9 & - & & No \\
\hline 5 & $\mathrm{~F}$ & 7 years 8 months & $\mathrm{M}$ & $\mathrm{A}, \mathrm{S}$ & - & Clinical & Normal & 17 & CBZ & Yes & No \\
\hline 6 & $\mathrm{M}$ & 4 years 9 months & $\mathrm{M}$ & $\mathrm{A}, \mathrm{S}$ & - & Clinical and subclinical & Normal & 5 & $\mathrm{VPA}+\mathrm{CLB}$ & No & Yes \\
\hline 7 & $\mathrm{~F}$ & 3 years 9 months & PA & $\mathrm{A}, \mathrm{S}$ & Yes & Clinical and subclinical & Normal & 5 & $\mathrm{ESM}+\mathrm{CLB}$ & No & Yes \\
\hline 8 & $\mathrm{~F}$ & 11 years & PA & $\mathrm{S}$ & - & Clinical & Normal & 10 & VPA & Yes & No \\
\hline 9 & $\mathrm{~F}$ & 2 years 4 months & PA & $\mathrm{S}$ & Yes & Clinical & Normal & 10 & CLB & Yes & Yes \\
\hline 10 & M & 2 years & M & S & - & Clinical & TND & 11 & $\mathrm{VPA}+\mathrm{CLB}$ & No & Yes \\
\hline 11 & M & 6 years & M & $\mathrm{S}$ & - & Clinical & TND & 3 & - & No & Yes \\
\hline 12 & $\mathrm{~F}$ & 3 years 9 months & M & $\mathrm{S}$ & - & Clinical & TND & 10 & LTG & No & Yes \\
\hline 13 & M & 3 years 6 months & M & $\mathrm{S}$ & Yes & Clinical & TND & 4 & LEV & Yes & No \\
\hline 14 & M & 5 years 6 months & M & A, S & - & Clinical and subclinical & Normal & 5 & CLB & Yes & No \\
\hline 15 & M & 8 years & PA & $\mathrm{S}$ & Yes & Clinical & Normal & 13 & - & & No \\
\hline 16 & $\mathrm{~F}$ & 7 years & PA & $\mathrm{S}$ & Yes & Clinical & Normal & 3 & - & & No \\
\hline 17 & M & 5 years 10 months & M & $\mathrm{S}$ & - & Clinical & Normal & 4 & VPA & Yes & No \\
\hline 18 & $\mathrm{~F}$ & 7 years & PA & $\mathrm{S}$ & - & Clinical & Normal & 3 & VPA & & No \\
\hline 19 & $\mathrm{~F}$ & 9 years 9 months & PA & $\mathrm{S}$ & - & Clinical & $\begin{array}{l}\text { Behavioural } \\
\text { problems }\end{array}$ & 3 & VPA & Yes & No \\
\hline 20 & $\mathrm{M}$ & 5 years 8 months & PA & $\mathrm{A}, \mathrm{S}$ & & Clinical & Normal & 4 & - & No & No \\
\hline 21 & M & 7 years & PA & $\mathrm{S}$ & Yes & Clinical & Learning difficulties & 7 & $\mathrm{VPA}+\mathrm{ESM}$ & No & No \\
\hline 22 & M & 3 years & M & A, S & - & Clinical & $\begin{array}{l}\text { Attention deficit, } \\
\text { learning difficulties }\end{array}$ & 7 & $\mathrm{VPA}+\mathrm{CLB}+\mathrm{TPM}$ & No & Yes \\
\hline 23 & $\mathrm{M}$ & 8 years 8 months & PA & $\mathrm{S}$ & Yes & Clinical & Normal & 8 & VPA & Yes & No \\
\hline 24 & M & 6 years 6 months & $\mathrm{M}$ & $\mathrm{S}$ & - & Clinical & Normal & 3 & - & & No \\
\hline 25 & M & 9 years 11 months & PA & $\mathrm{S}$ & Yes & Clinical & Normal & 3 & VPA + LEV & No & Yes \\
\hline 26 & $\mathrm{~F}$ & 7 years & PA & $\mathrm{S}$ & - & Clinical & Normal & 15 & CBZ & No & Yes \\
\hline 27 & M & 6 years 6 months & PA & $\mathrm{S}$ & - & Clinical & Normal & 10 & $\mathrm{CBZ}$ & No & No \\
\hline 28 & M & 9 months & PA & $\mathrm{S}$ & - & Clinical & Normal & 8 & $\mathrm{CBZ}$ & Yes & No \\
\hline 29 & M & 8 years & PA & $\mathrm{S}$ & Yes & Clinical & Normal & 3 & VPA & Yes & Yes \\
\hline 30 & M & 8 years & M & $\mathrm{A}, \mathrm{S}$ & - & Clinical & Normal & 9 & VPA & Yes & Yes \\
\hline
\end{tabular}

PA, Pluriannual; M, monthly; A, awake S, sleep; TND, transient neuropsychological deficit; VPA, valproic acid; CLB, clobazam; CBZ, carbamazepine; ESM, ethosuximide; LTG, lamotrigine; LEV, levetiracetam; TPM, topiramate; AEDs RES, response to antiepileptic drug. 
Table 2

Detailed ictal semeiology in the BECTS patients reported by the parents and observed at video-EEG recording.

\begin{tabular}{|c|c|c|}
\hline Patient no. & Parents description & Video-EEG (ictal semeiology) \\
\hline 1 & Cry, right perioral and right arm twitching, anarthria & Hemifacial right twitching, anarthria \\
\hline 2 & Cry, hemifacial right twitching then of right limbs & Subclinical \\
\hline 3 & $\begin{array}{l}\text { Mouth deviation to the right, right arm twitching, } \\
\text { dysarthria }\end{array}$ & Look frightened, right arm clonic movements, anarthria \\
\hline 4 & Guttural sounds, right perioral twitching, anarthria & Subclinical \\
\hline 5 & Look frightened, tremor, fixed gaze & Look frightened, left arm twitching \\
\hline 6 & Hemifacial twitching & Left hemifacial twitching then of left arm \\
\hline 7 & Hemifacial twitching & $\begin{array}{l}\text { Left hemifacial twitching, then involvement of the left } \\
\text { side of the body }\end{array}$ \\
\hline 8 & Perioral twitching & $\begin{array}{l}\text { Right perioral twitching, then of the four limbs and loss } \\
\text { of consciousness }\end{array}$ \\
\hline 9 & Hemisomic clonic jerks & $\begin{array}{l}\text { Left arm and hemifacial twitching, then of the left side } \\
\text { of the body, loss of consciousness }\end{array}$ \\
\hline 10 & Hemifacial clonic jerks & Left hemifacial and arm twitching \\
\hline 11 & $\begin{array}{l}\text { (a) Stertorous respiration, right hemifacial and arm } \\
\text { twitching, loss of consciousness } \\
\text { (b) Twitching of the right side of the body }\end{array}$ & $\begin{array}{l}\text { Right perioral twitching, hemifacial twitching, right arm } \\
\text { extension, loss of consciousness }\end{array}$ \\
\hline 12 & Head deviation, clonic jerks & $\begin{array}{l}\text { Head and eye deviation to the left or to the right, } \\
\text { hemiclonic left or right seizure }\end{array}$ \\
\hline 13 & Perioral and arm clonic movements & $\begin{array}{l}\text { Perioral and arm twitching with secondary } \\
\text { generalization }\end{array}$ \\
\hline 14 & $\begin{array}{l}\text { Mouth deviation to the left and left hemifacial } \\
\text { twitching }\end{array}$ & $\begin{array}{l}\text { Tongue paresthesia, touching the mouth with left hand, } \\
\text { cry, retching, drooling, difficult respiration, clonic } \\
\text { movement of the four limbs }\end{array}$ \\
\hline 15 & Hemifacial right twitching, anarthria & $\begin{array}{l}\text { Awakening, right hemifacial twitching, anarthria, } \\
\text { drooling }\end{array}$ \\
\hline 16 & $\begin{array}{l}\text { Crying, eye deviation to the right, trisma, diffuse } \\
\text { hypertonus, with or without clonic phase }\end{array}$ & Left arm paresthesia \\
\hline 17 & $\begin{array}{l}\text { Crying, mouth deviation, loss of contact, eyelid } \\
\text { myoclonia, hypertonus }\end{array}$ & $\begin{array}{l}\text { Eye opening, right perioral twitching then involvement } \\
\text { of eye, arm and leg of the same side }\end{array}$ \\
\hline 18 & Not possible to close mouth & $\begin{array}{l}\text { Perioral left twitching, then involvement of left eye, arm } \\
\text { and leg }\end{array}$ \\
\hline 19 & $\begin{array}{l}\text { Guttural sounds, diffuse hypertonus, arm clonic } \\
\text { movements }\end{array}$ & Mouth deviation, secondary generalization \\
\hline 20 & $\begin{array}{l}\text { Hypertonus, four limbs clonic movements, loss of } \\
\text { consciousness }\end{array}$ & $\begin{array}{l}\text { Eye and mouth deviation to the left, secondary } \\
\text { generalization }\end{array}$ \\
\hline 21 & Right hemifacial and right arm clonic movements & $\begin{array}{l}\text { Eye, head and mouth deviation to the right, drooling, } \\
\text { loss of consciousness }\end{array}$ \\
\hline 22 & Perioral right twitching & Mouth deviation to the right, loss of contact \\
\hline 23 & Clonic generalized & $\begin{array}{l}\text { Diffuse hypertonus, trunk rotation toward left, limb } \\
\text { extension, loss of contact, chewing movements }\end{array}$ \\
\hline 24 & Hemifacial jerking & $\begin{array}{l}\text { Left deviation of the mouth, dysarthria, hemifacial } \\
\text { jerking }\end{array}$ \\
\hline 25 & Left facial and left arm jerking & $\begin{array}{l}\text { Dystonic posturing of left hand, then of left arm, head } \\
\text { deviation toward the left, hypertonus and clonic } \\
\text { movement }\end{array}$ \\
\hline 26 & Clonic generalized & Left hemifacial twitching \\
\hline 27 & Facial twitching & Blows, left mouth deviation \\
\hline 28 & Perioral twitching, anarthria & Right perioral twitching, anarthria, drooling \\
\hline 29 & Guttural sounds, drooling, anarthria & $\begin{array}{l}\text { Anarthria, drooling, right hemisomic twitching, } \\
\text { secondary generalization }\end{array}$ \\
\hline 30 & Guttural sounds, drooling & Drooling, right hemifacial and arm twitching \\
\hline
\end{tabular}

\subsection{Therapy}

All patients except seven have been treated with AEDs: 17 children were treated in monotherapy (four with carbamazepine, eight with valproic acid, three with clobazam, one with levetiracetam and one with lamotri- gine), six patients received concomitant therapy with two (four patients) or more than two (two patients) AEDs.

More than one AED was introduced because of frequent seizures or because of neuropsychological impairment. 
Table 3

EEG features of the seizures recorded in 30 patients.

\begin{tabular}{|c|c|c|c|c|c|c|c|c|c|}
\hline Patient no. & Initial ictal pattern & $\begin{array}{l}\text { Ictal discharge } \\
\text { modification }\end{array}$ & $\begin{array}{l}\text { Clinical seizure } \\
\text { duration }\end{array}$ & $\begin{array}{l}\text { Post-ictal } \\
\text { slowing }\end{array}$ & $\begin{array}{l}\text { Subclinical } \\
\text { pattern }\end{array}$ & $\begin{array}{l}\text { Subclinical } \\
\text { seizure } \\
\text { duration }\end{array}$ & Ictal side & SEC GEN & $\begin{array}{l}\text { IND BIL } \\
\text { ABN }\end{array}$ \\
\hline 1 & Pattern A & Yes & $3 \min$ & No & - & - & Left & No & No \\
\hline $2^{\mathrm{a}}$ & - & - & - & No & Pattern A & $20 \mathrm{~s}$ & Left & No & No \\
\hline 3 & Pattern D & Yes & $1 \mathrm{~min}$ & Yes & & - & Left & No & No \\
\hline $4^{\mathrm{a}}$ & - & - & - & No & Pattern A & $10 \mathrm{~s}$ & Right & No & Yes \\
\hline 5 & Pattern B & Not & $30 \mathrm{~s}$ & No & - & - & Right & No & Yes \\
\hline 6 & Pattern A & Not & $45 \mathrm{~s}$ & No & Pattern C & $25 \mathrm{~s}$ & Right & No & Yes \\
\hline 7 & Pattern B & Yes & $15 \mathrm{~min}$ & Yes & Pattern B, C & $15 \mathrm{~s}$ & Right/left & No & Yes \\
\hline 8 & Pattern A & Yes & $2 \mathrm{~min}$ & No & - & - & Left & Yes & No \\
\hline 9 & Pattern B & Yes & $5 \min 30 s$ & Yes & - & - & Right & No & No \\
\hline 10 & Pattern B & Not & $1 \mathrm{~min} 10 \mathrm{~s}$ & No & - & - & Right & No & No \\
\hline 11 & Pattern D & Yes & $1 \mathrm{~min}$ & No & - & - & Right & No & Yes \\
\hline 12 & Pattern A & Not & $3 \mathrm{~min}$ & No & - & - & Left & No & Yes \\
\hline 13 & Pattern C & Yes & $3 \mathrm{~min}$ & Yes & - & - & Left & Yes & Yes \\
\hline 14 & Pattern A & Not & $2 \min 15 s$ & No & Pattern A & $15 \mathrm{~s}$ & Right & No & No \\
\hline 15 & Pattern A & Yes & $40 \mathrm{~s}$ & No & - & - & Left & No & No \\
\hline 16 & Pattern A & Yes & $50 \mathrm{~s}$ & No & - & - & Right & No & No \\
\hline 17 & Pattern C & Yes & $80 \mathrm{~s}$ & No & - & - & Left & No & Yes \\
\hline 18 & Pattern A & Yes & $2 \mathrm{~min}$ & No & - & - & Left & Yes & No \\
\hline 19 & Pattern B & Not & $2 \min 15 s$ & Yes & - & - & Left & Yes & Yes \\
\hline 20 & Pattern D & Yes & $3 \mathrm{~min}$ & No & - & - & Right & Yes & Yes \\
\hline 21 & Pattern B & Yes & $100 \mathrm{~s}$ & No & - & - & Left & No & No \\
\hline 22 & Pattern D & Yes & $50 \mathrm{~s}$ & No & - & - & Left & No & Yes \\
\hline 23 & Pattern C & Yes & $2 \min$ & No & - & - & Left & No & Yes \\
\hline 24 & Pattern C & Yes & $50 \mathrm{~s}$ & No & - & - & Right & No & No \\
\hline 25 & Pattern C & Yes & $50 \mathrm{~s}$ & Yes & - & - & Left & No & Yes \\
\hline 26 & Pattern A & Yes & $65 \mathrm{~s}$ & No & - & - & Right & No & No \\
\hline 27 & Pattern D & Yes & $16 \mathrm{~s}$ & Yes & - & - & Right & No & No \\
\hline 28 & Pattern A & Yes & $15 \mathrm{~min}$ & No & - & - & Right & No & No \\
\hline 29 & Pattern A & Yes & $25 \mathrm{~s}$ & No & - & - & Left & Yes & Yes \\
\hline 30 & Pattern A & Not & $40 \mathrm{~s}$ & No & - & - & Left & No & Yes \\
\hline
\end{tabular}

SEC GEN, Secondary generalization; IND BIL ABN, independent bilateral abnormalities.

${ }^{\text {a }}$ Only subclinical seizure recorded.

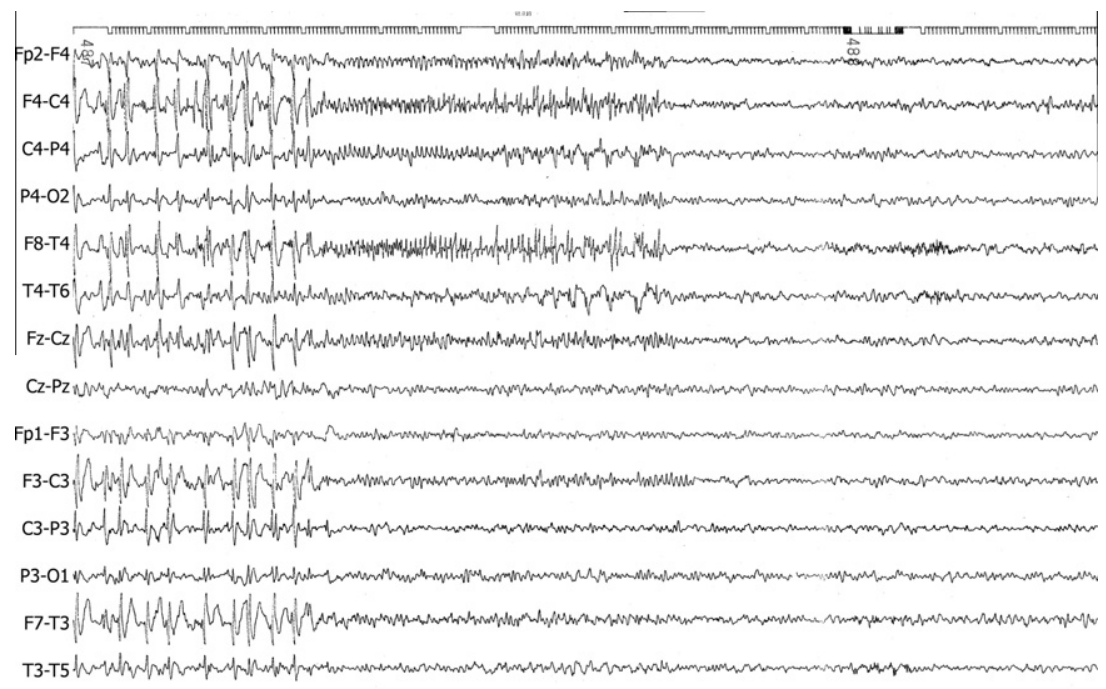

Fig. 1. Subclinical ictal event, lasting $10 \mathrm{~s}$, characterized by a low voltage fast activity of rhythmic spikes, increasing in amplitude and decreasing in frequency over right centro-temporal regions (pattern A, patient no. 4). 


\subsection{Follow-up}

All patients have a follow-up more then 3 years (range 3-18 years from the beginning of disease, mean value 7 years).

\subsection{EEG picture}

\subsubsection{Interictal findings}

All the patients showed typical interictal EEG findings consistent with diagnosis of BCECTS. Fourteen patients presented with independent EEG foci. EEG paroxysms increased during sleep in all the patients, without any change in their morphology. Two out of the patients had an EEG pattern typical of Electrical Status Epileptics during Sleep (Cases 21 and 22).

\subsubsection{Ictal findings}

Electroclinical seizures were recorded in 28 patients. In three of these children we recorded also subclinical episodes, lasting from 10 to 25 seconds. In two adjunctive patients we recorded only subclinical events. Sei-

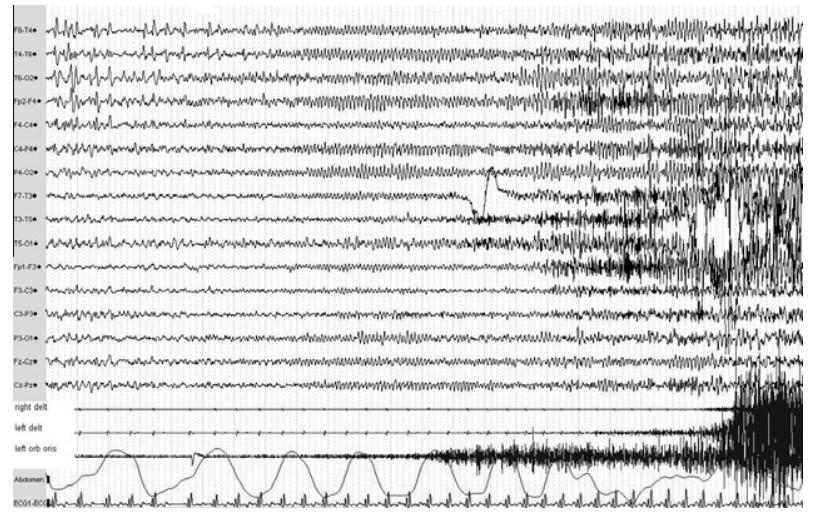

Fig. 4. Initial phase of a clinical event lasting $50 \mathrm{~s}$ characterized by dysarthria, left deviation of the mouth and hemifacial jerks. Theta activity (pattern C) starting from right centro-temporal regions after interruption of interictal abnormalities is evident. After few seconds note the change to pattern A for some seconds and, finally, to pattern C (patient no. 24).

zures started from right hemisphere in 13 children, from left hemisphere in 16. A girl presented seizures starting from both hemispheres. Ictal morphology could

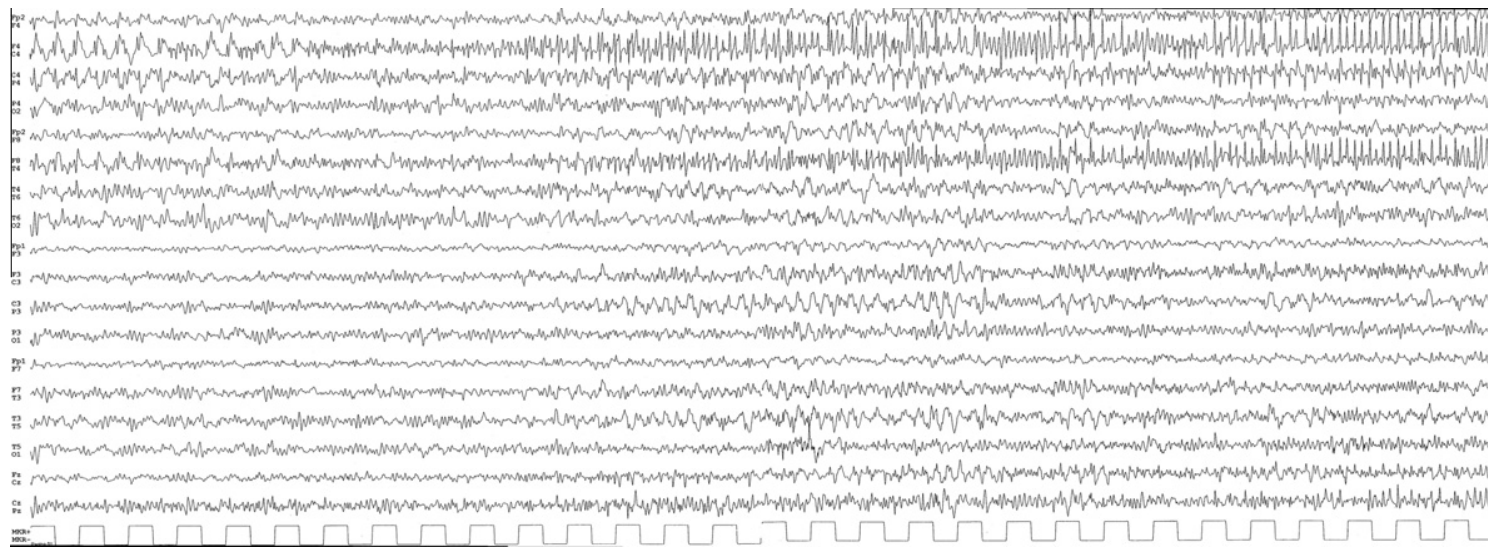

Fig. 2. Start of a clinical ictal event lasting $1 \mathrm{~min}$ and $10 \mathrm{~s}$ with left hemifacial and arm twitching. Note spike and wave discharge involving right centro-temporal regions (pattern B) evolving into a theta activity (pattern C) and then again returning to spike and wave activity (pattern B, patient no. 10).

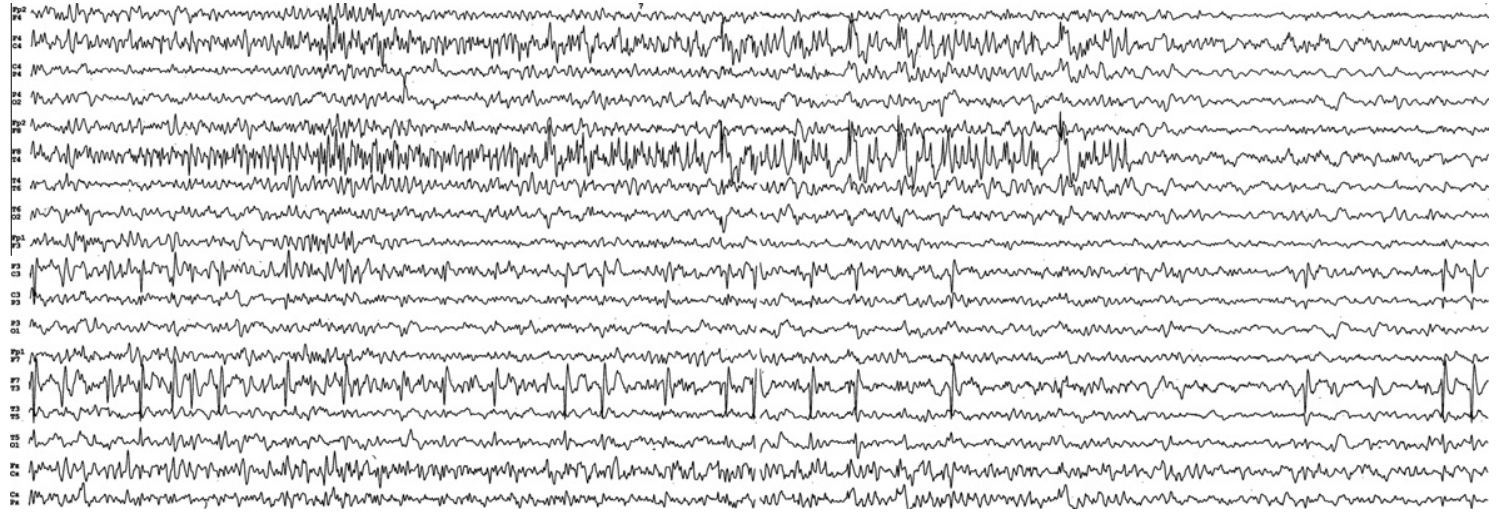

Fig. 3. Subclinical seizure lasting $15 \mathrm{~s}$, constituted by a discharge of spikes intermixed with sharp waves increasing in frequency and amplitude over the time, involving right centro-temporal regions (pattern B, patient no. 7). 
change during the seizure and Table 3 shows the EEG features of each episode. So, we describe both the initial ictal pattern and the subsequent ictal development. We recognized four different starting ictal patterns in our children. The first is characterized by low voltage activity of fast rhythmic spikes, increasing in amplitude and decreasing in frequency (pattern A), and it was found in 10 children with clinical seizures, in two with subclinical events and in two with both (Fig. 1). The second EEG pattern is constituted by a discharge of spikes intermixed with sharp waves increasing in frequency and amplitude over the time (pattern B), and can be found in five children with clinical seizures and in one patient with subclinical seizures (Figs. 2 and 3). The third ictal pattern is characterized by monomorphous theta activity which progressively formed a discharge increasing in amplitude and decreasing in frequency (pattern C) and it was found in five children with clinical seizures and in two children with subclinical seizures (Figs. 4 and 5). Finally, the fourth and last ictal pattern (pattern D), found in five cases, is characterized by an initial phase of focal depression of the electrical activity followed by one of the three above described patterns and it was always accompanied by clinical symptoms (Fig. 6). In 21 out of 28 children, the initial ictal pattern could modify during the seizure, resulting in a switch from one pattern to another one (Table 3; Figs. 2 and 5-7). Patients featuring patterns $\mathrm{C}$ and D constantly showed a modification of the ictal discharge over the time. Secondary generalization, present in six cases, was related to all four different initial ictal patterns and to both unilateral and independent EEG foci. Post-ictal slowing (Fig. 8) was encountered after seven clinical seizures, without association with a particular ictal pattern. In the three cases with more than an unique recorded seizures, we noted that the morphology

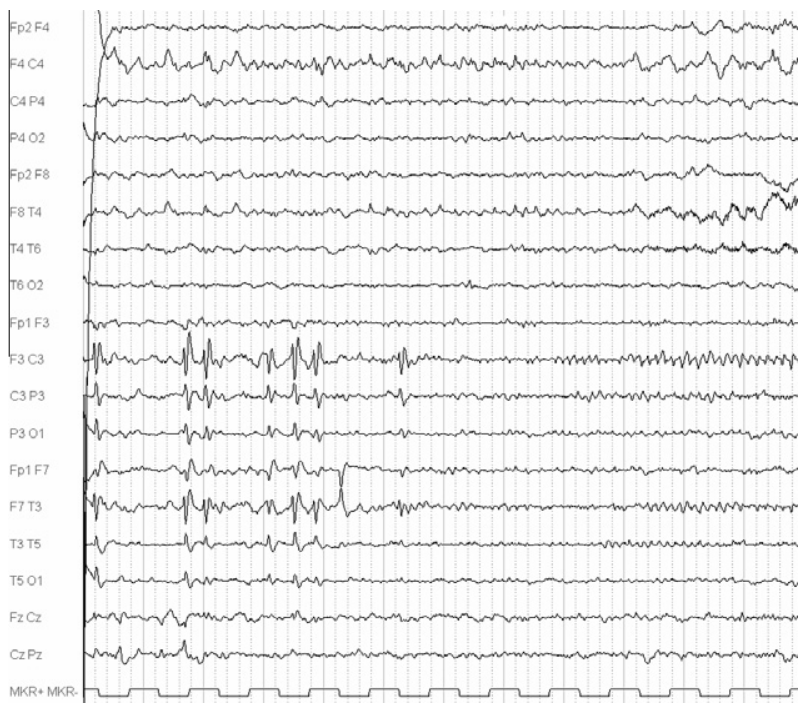

Fig. 6. Initial phase of a clinical seizure lasting $1 \mathrm{~min}$ and characterized by right perioral and hemifacial twitching, right arm extension, loss of consciousness. Note the focal depression of electrical activity (pattern D) followed subsequently by theta activity (pattern C) on left central region (patient no. 11).

of the whole ictal discharge could be different in different episodes.

\subsection{Statistical analysis}

Statistical analysis is shown in Table 4. No clinical or EEG feature was predictive of a specific ictal pattern except for post-ictal slowing, which was never associated to pattern A $(p=0.01)$.

\section{Discussion}

Our paper includes a very important number of cases with recorded seizure and they represent, at our best

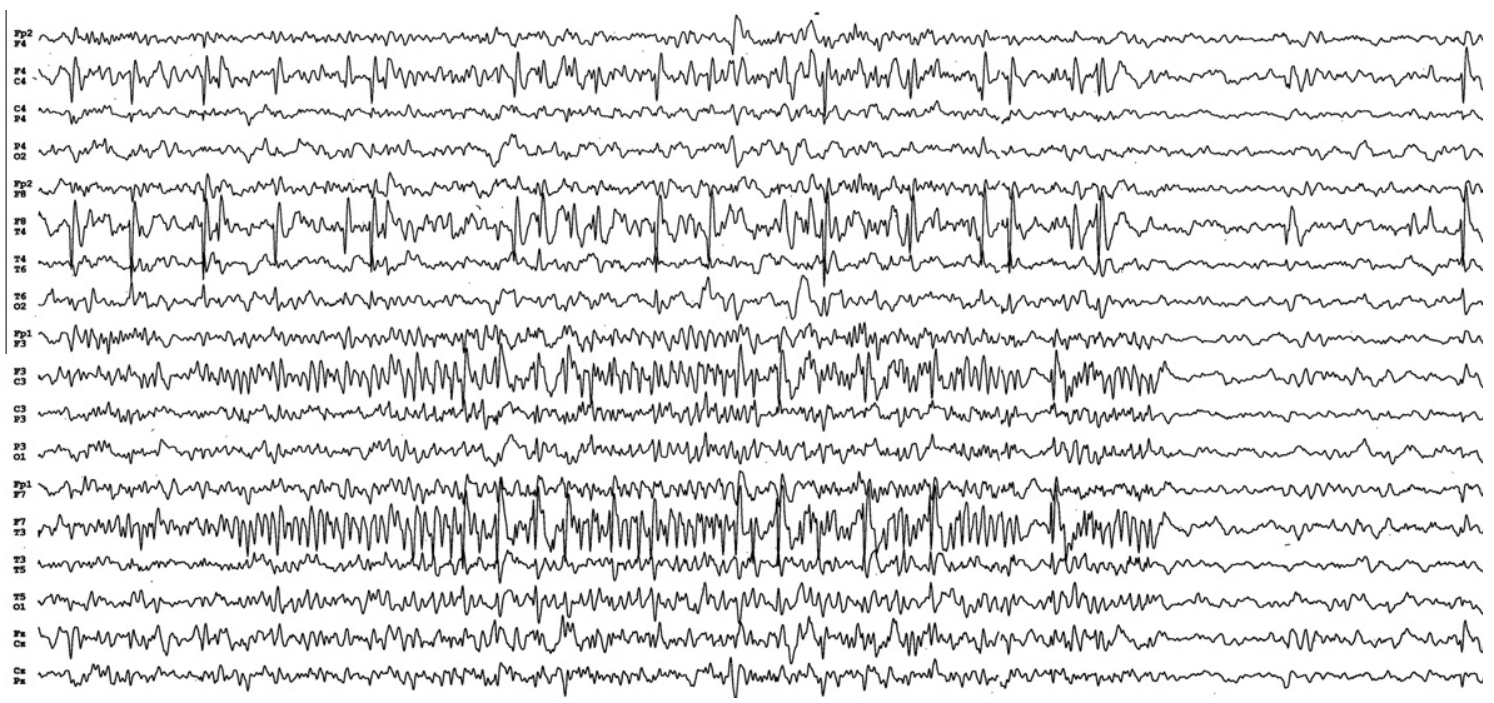

Fig. 5. Subclinical ictal event lasting $15 \mathrm{~s}$. Monomorphous theta activity is evident on left centro-temporal regions (pattern C) evolving into spike and wave discharge (pattern B, same patient and same registration of Fig. 3). 


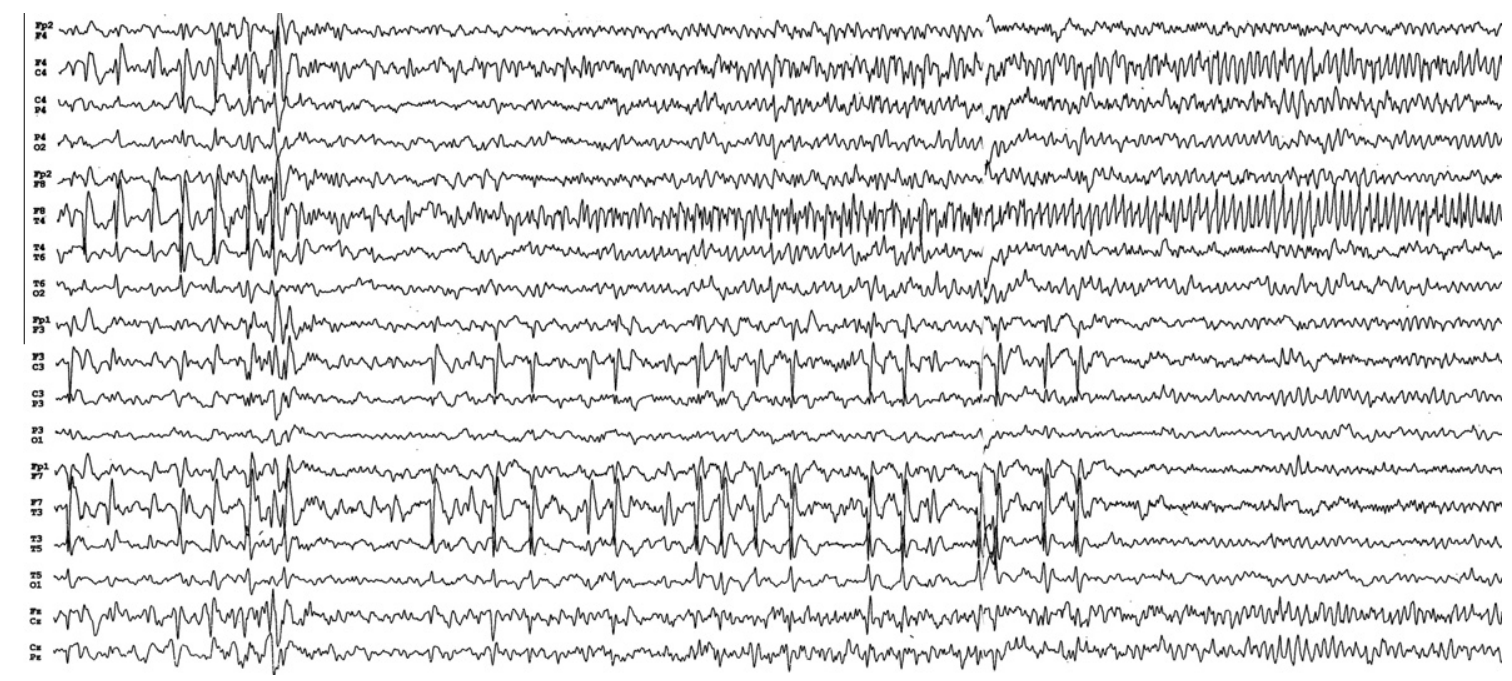

Fig. 7. Initial part of a clinical seizure with left hemifacial twitching and then involvement of the left side of the body lasting 15 min. Note: spike and wave discharge on right centro-temporal regions (pattern B) evolving into theta activity (pattern C, same patient of Fig. 3 ).

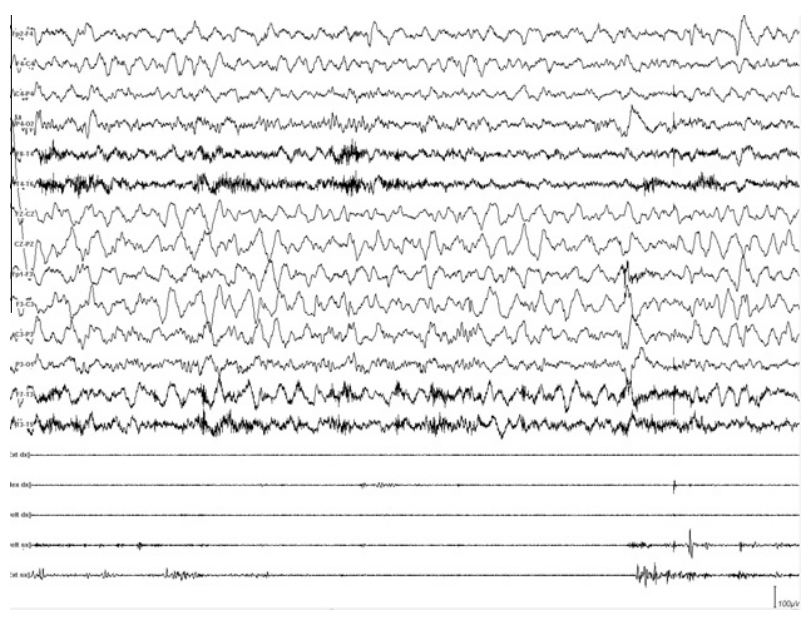

Fig. 8. Post-ictal slowing is evident on the left centro-temporal and vertex regions after some minutes from seizure stop (patient no. 3).

knowledge, not only the more relevant number of BCECTS patients with recorded seizures ever described in an article but also the overwhelming majority of patients with BCECTS seizures ever described. The absolute relevance of our contribution is the striking evidence that, differently from the literature statements, a unique ictal pattern does not exist in rolandic epilepsy and that, on the contrary, clear differences are present for the ictal EEG patterns. The morphology of the ictal discharge, for example, varies greatly in different patients (sometimes in the same patient), as is well evident from our iconographic documentation. So, the evidence that an unique typical ictal EEG pattern does not exist in BCECTS, as believed after the first descriptions, is of particular interest in the daily clinical practice. In fact, it is not so rare the second opinion observation of patients who have had excluded BCECTS diagnosis for their seizure characteristics. Even if scarce are the relative descriptions, this ictal variability is similar to another idiopathic benign focal condition, i.e. occipital childhood epilepsy, in particular for the early variant described by Panayiotopoulos [14]. On the contrary, literature data evidence that stereotyped ictal manifestations are common in focal epilepsy sustained by different cortical pathologies, such as malformations of cortical development and cerebral tumors [15]. The possible explanation of these different ways of presentation can primarily although not exclusively - lie in the functional nature

Table 4

Correlation between the four identified ictal patterns and the clinical-EEG features of the 30 patients.

\begin{tabular}{lllll}
\hline Pattern type $(n=30)$ & $\begin{array}{l}\text { Ictal abnormalities } \\
\text { side }(\mathrm{L} / \mathrm{R})\end{array}$ & $\begin{array}{l}\text { Secondary } \\
\text { generalization }(\mathrm{Y} / \mathrm{N})\end{array}$ & $\begin{array}{l}\text { Post-ictal } \\
\text { slowing }(\mathrm{Y} / \mathrm{N})\end{array}$ & $\begin{array}{l}\text { Drug-resistance } \\
(\mathrm{Y} / \mathrm{N})\end{array}$ \\
\hline Pattern A $(n=14)$ & $8 / 6$ & $3 / 11$ & $0 / 14^{*}$ & $4 / 10$ \\
Pattern B $(n=6)$ & $3 / 4^{\mathrm{b}}$ & $1 / 5$ & $3 / 3$ & $3 / 3$ \\
Pattern C $(n=7)$ & $5 / 2$ & $2 / 5$ & $2 / 5$ & $3 / 4$ \\
Pattern D $(n=5)$ & $2 / 3$ & $1 / 4$ & $2 / 3$ & $4 / 1$ \\
\hline
\end{tabular}

L, Left; R, right; Y, yes; N, no.

${ }^{a}$ Three children did not receive antiepileptic therapy.

b In patient 7 the ictal discharge started independently from both hemispheres.

${ }^{*} p=0.01$. 
of BCECTS, so that seizures can have different ictal morphology and localization. This hypothesis is also reinforced by the same behavior in Panayiotopoulos syndrome and can be well explained by the theory of the so called "system epilepsy" recently advanced by Wolf in 2006 [16] and, more recently, by Koutroumanidis [17] and Capovilla et al. [18]. Another interesting feature of our series of patients is that in 21 children ictal discharge changed its morphology during the seizure and that, in seven patients, the EEG showed a post-ictal slowing. Also these EEG features are in contrast with the literature statements. Moreover, a focal neurological post-ictal deficit is not so rare since it was observed in 11 children, confirming some previous anecdotal observations [9] and it was not regularly related to a post-ictal slowing. In conclusion, we provided evidence - in the largest series of BCECTS patients reported to date - that a unique ictal pattern does not exist in BCECTS, in contrast with the opinion of other authors [1,2]. Moreover, the presence of "per-ictal" features such as EEG depression before the seizures and post-ictal slowing do not exclude BCECTS diagnosis. Again, an ictal pattern modification is not conflicting with BCECTS diagnosis. We therefore suggest that the diagnosis of BCECTS should be firstly put on the basis of the global clinical context assessment. These data provide a significant contribution both in correctly diagnosing BCECTS and in understanding its physiopathology.

\section{Conflicts of interest}

The authors report no conflicts of interest.

\section{Acknowledgments}

We thank the technicians who recorded the seizures.

We confirm that we have read the Journal's position on issues involved in ethical publication and affirm that this report is consistent with those guidelines.

\section{References}

[1] Dalla Bernardina B, Sgrò V, Fejerman N. Epilepsy with centrotemporal spikes and related syndromes. In: Roger J, Bureau M, Dravet C, Genton P, Tassinari CA, Wolf P, editors. Epileptic syndromes in infancy, childhood and adolescence. London: John Libbey \& Company Ltd.; 2005. p. 203-25.
[2] Fejerman N, Caraballo RH, Dalla Bernardina B. Benign childhood epilepsy with centrotemporal spikes. In: Fejerman $\mathrm{N}$, Caraballo RH, editors. Benign focal epilepsies in infancy, childhood and adolescence. Montrouge: John Libbey Eurotext; 2007. p. 77-113.

[3] Ambrosetto G, Gobbi G. Benign epilepsy of childhood with rolandic spikes, or a lesion? EEG during a seizure. Epilepsia 1975;16:793-6.

[4] Dalla Bernardina B, Tassinari CA. EEG of a nocturnal seizure in a patient with "Benign Epilepsy of Childhood with Rolandic Spikes”. Epilepsia 1975;16:497-501.

[5] Gutierrez AR, Brick JF, Bodensteiner J. Dipole reversal: an ictal feature of benign partial epilepsy with centrotemporal spikes. Epilepsia 1990;31:544-8.

[6] Veggiotti P, Beccaria F, Gatti A, Papalia G, Resi C, Lanzi G. Can protrusion of the tongue stop seizures in rolandic epilepsy? Epil Disord 1999;1:217-20.

[7] Clemens B. Ictal electroencephalography in a case of benign centrotemporal epilepsy. J Child Neurol 2002;17:297-300.

[8] Oliveira de Andrade D. Padrao eletrografico ictal subclinico em um caso de epilepsia parcial benigna da infancia com pontas centro-temporais. Arq Neuropsiquiatr 2005;63(2A):360-3.

[9] Dai AI, Weinstock A. Postictal paresis in children with benign rolandic epilepsy. J Child Neurol 2005;20:834-6.

[10] Saint-Martin AD, Carcangiu R, Arzimanoglou A, Massa R, Thomas $\mathrm{P}$, Motte $\mathrm{J}$, et al. Semiology of typical and atypical Rolandic epilepsy: a video-EEG analysis. Epil Disord 2001;3:173-82.

[11] Aicardi J. Epilepsies characterized by simple partial seizures. In: Aicardi J, editor. Epilepsy in children. New York: Raven Press; 1994. p. $130-64$.

[12] Commission on Classification and Terminology: proposal for revised classification of epilepsies and epileptic syndromes. Epilepsia 1989;30:389-99.

[13] Engel J. A proposed diagnostic scheme for people with epileptic seizures and with epilepsy: report of the ILAE Task Force on Classification and Terminology. Epilepsia 2001;42:796-803.

[14] Panayiotopoulos CP. Panayiotopoulos syndrome: a common and benign childhood epileptic syndrome. London: John Libbey \& Company; 2002.

[15] Kahane P, Arzimanoglou A, Bureau M, Roger J. Non-idiopathic partial epilepsies of childhood. In: Roger J, Bureau M, Dravet C, Genton P, Tassinari CA, Wolf P, editors. Epileptic syndromes in infancy, childhood and adolescence. London: John Libbey \& Company Ltd.; 2005. p. 255-75.

[16] Wolf P. Basic principles of the ILAE Syndrome classification. Epil Res 2006;1:20-6.

[17] Koutroumanidis M. Panayiotopoulos syndrome: an important electroclinical example of benign childhood system epilepsy. Epilepsia 2007;48:1044-53.

[18] Capovilla G, Berg AT, Cross JH, Moshe SL, Vigevano F, Wolf P, et al. Conceptual dichotomies in classifying epilepsies: partial versus generalized and idiopathic versus symptomatic. Epilepsia 2009;50:1645-56, [Workshop report (April 18-20, 2008, Monreale, Italy)]. 